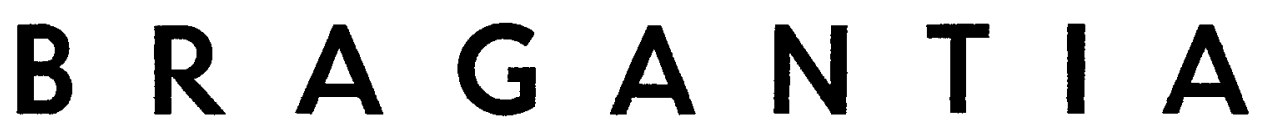

Revista Cientifica do Instituto Agronômico do Estado de Sāo Paulo

Vol. 37

Campinas, janeiro de 1978

N. ${ }^{\circ} 2$

\title{
EFEITO DE ALTA TEMPERATURA NO DESENVOLVIMENTO DE HEMILEIA VASTATRIX EM CAFEEIRO SUSCETIVEL ${ }^{\left({ }^{(}\right)}$
}

Ivan José Antunes Riberro $\left({ }^{2}\right)$, Seção de Microbiologia Fitotécnica, Lourival CaRmo Monaco $\left({ }^{2}\right)$, Seção de Genética, Otávio Trsseldi Filho è Mauro Hideo SugimoRI $\left(^{2}\right)$, Seção de Microbiologia Fitotécnica, Instituto Agronômico

\section{SINOPSE}

Foi estudado o efeito de temperaturas elevadas no desenvolvimento da ferrugem do cafeeiro, verificando-se que a exposiçäo de plantas a temperatura próxima de $40^{\circ} \mathrm{C}$ por quatro horas durante quatro dias fol suficiente para impedir a evolução da moléstia.

Períodos menores foram ineficientes para afetar o desenvolvimento do fungo.

\section{1 - INTRODUÇĀO}

O efeito desfavorável de temperaturas elevadas no desenvolvimento das ferrugens tem sido fartamente demonstrado na literatura.

Hart e Zaleski (4) verificaram que plantas de trigo mantidas a $26 \mathrm{e}$ $33^{\circ} \mathrm{C}$ não apresentavam formação de pústulas quando inoculadas com Puccinia graminis tritici, mostrando reação caracterizada como de resistência. Semelhantes resultados foram obtidos por Johnson e Newton (7) para diversas espécies de Puccinia, À medida que a temperatura era ele- vada acima do ótimo para o desenvolvimento da ferrugem, o tipo de reação suscetível observada em condições normais passava para reação de hipersensibilidade. Essa reação diferencial foi caracterizada para Puccinia glumarum. Variedades suscetíveis em condições normais se comportavam como resistentes em plantios no verão, em virtude da elevada sensibilidade dessa ferrugem às altas temperaturas. $O$ termo "Sommerresistenz" foi sugerido para caracterizar essa reação. Oliveira

(1) Trabalho apresentado no $1 .^{\circ}$ Congresso Brasileiro Sobre Pragas e Doenças do Cafeeiro Vitória, ES, em 4 a 6 de julho de 1973. Recebido para publicação em 2 de abril de 1977.

(2) Com bolsa de suplementação do C.N.Pq. 
Vol. 3., N.० 2

(11) mostrou que plantas de cevada inoculadas com Puccinia anomala, mantidas a $30^{\circ} \mathrm{C}$ por 15 dias, apresentavam apenas reações clorótioas ou necróticas. A continuidade do tratamento não foi essencial, pois mesmo em condições alternadas de temperaturas elevada e normal, o efeito prejudicial da temperatura era observado na manifestação dos sintomas.

O efeito inverso na reação patógeno-hospedeiro foi verificado com variedades resistentes, quando submetidas a tratamentos térmicos. Johnson e Newton (8) demonstraram que variedades de trigo resistentes a Puccinia graminis tritici tornavam-se suscetíveis quando a temperatura em que eram cultivadas se elevava a $26^{\circ} \mathrm{C}$.

Futrell e Rivers (3) mostraram que "seedlings" de variedades e seleções de aveia resistentes a Puccinia coronata var. avenae a $20^{\circ} \mathrm{C}$, tornam-se suscetíveis a $30^{\circ} \mathrm{C}$ sendo o aumento na suscetibilidade inversamente correlacionado com a intensidade luminosa e o comprimento do dia.

A viabilidade dos uredosporos é igualmente afetada pelas altas temperaturas. Hobbs (5) mostrou que uredosporos de Puccinia coronata produzidos em plantas de aveia mantidas a $16^{\circ} \mathrm{C}$ germinam em porcentagens duas a três vezes maiores do que os produzidos a $22^{\circ} \mathrm{C}$ ou $30^{\circ} \mathrm{C}$. A longevidade dos uredosporos foi igualmente afetada pela temperatura em que foram produzidos.

Hwang (6) obteve resultados semelhantes para diversas espécies de Puccinia. Eversmeyer e Burleigh (2) mostraram que os uredosporos de Puccinia recondita f. sp. tritici a $5-8^{\circ} \mathrm{C}$ permanecem viáveis por 45 dias em folhas de trigo secas e apenas 9 dias a $18-39^{\circ} \mathrm{C}$.

$O$ efeito da temperatura sobre - desenvolvimento - da Hemileia vastatrix e sobre a viabilidade dos uredosporos começou a despertar o interesse dos pesquisadores nas condições tropicais onde o café é cultivado. Esse conhecimento permitiria uma melhor definição da curva epidemiológica em função das temperaturas e ofereceria elementos seguros para controle à moléstia.

Os primeiros trabalhos foram de Nutman e Roberts (10), os quais determinaram que era $21^{\circ} \mathrm{C}$ a temperatura ótima para germinação e formação de apressórios, sendo em torno de $28,5^{\circ} \mathrm{C}$ a temperatura limitante para a germinação.

Em função da temperatura, o período de incubação de Hemileia vastatrix nas condições do Estado de São Paulo é menor nos meses mais quentes e aumenta nos meses mais frios. Todavia, ultrapassada a faixa adequada de temperatura, esse efeito passa a ser negativo. Assim, temperaturas superiores a $31^{\circ} \mathrm{C}$ aumentam o período de incubação, da mesma forma que as temperaturas baixas de inverno, como foi observado por Moraes e colab. (9). Também a longevidade do esporo é afetada pela temperatura $\left({ }^{3}\right)$. Esporos armazenados a $30^{\circ} \mathrm{C}$ mantêm a viabilidade por 14 a 19 dias, de acordo com a raça. Temperaturas entre 45 e $48^{\circ} \mathrm{C}$ reduzem a viabilidade para apenas 24 horas. 
A sensibilidade do fungo e seus esporos à variação de temperatura precisaria ser melhor conhecida para aprimorar o processo de controle. $O$ presente trabalho relata observações sobre o efeito de temperaturas elevadas sobre a infecção do cafeeiro por Hemileia vastatrix.

\section{2 - MATERIAL E MÉTODOS}

Lote homogêneo de mudas de café cV "mundo-novo", com seis meses de idade, foi selecionado para o estudo.

Folhas novas e tenras, porém já completamente desenvolvidas, foram inoculadas com uredosporos da raça II de Hemileia vastatrix, espalhados com auxílio de um pincel na face ventral do limbo foliar, sendo a planta em seguida pulverizada com água estéril.

Após a inoculação, as plantas foram mantidas 48 horas em câmara úmida, em luz difusa, para propiciar a germinação dos uredosporos e subsequiente penetração. Retiradas da câmara úmida, as plantas foram mantidas sob ripado, onde as temperaturas máximas e mínimas registradas em termógrafo não ultrapassaram os limites de 25 e $18^{\circ} \mathrm{C}$ respectivamente.

Vinte dias após a inoculação as folhas apresentavam numerosos pontos cloróticos. Nesse estádio, para os tratamentos térmicos as plantas foram colocadas em incubadoras tipo Biotronete II, iluminados com luz fluorescente, sendo de $50 \%$ a umidade relativa do ar. Foram testadas as temperaturas de 30,35 e $40^{\circ} \mathrm{C}$ e os tratamentos térmicos sempre realizados no período da tarde, após os quais as plantas retornavam ao ripado.

$\mathrm{O}$ tratamento térmico consistiu na exposição das plantas às diferentes temperaturas, durante um a seis dias, com duração diária de uma a quatro horas. Dessa forma foram obtidos, para cada temperatura, 24 tratamentos. A testemunha permaneceu sempre no ripado. De cada tratamento trabalhou-se com quatro repetições.

\section{3 - RESULTADOS}

As plantas tratadas apresentaram desenvolvimento vegetativo normal e idêntico às testemunhas, indicando que o choque térmico não provocou alterações sensíveis na fisiologia do cafeeiro. Nas plantas testemunhas e dos tratamentos a 30 e $35^{\circ} \mathrm{C}$ houve evolução de sintomas, levando à formação de pústulas típicas, com intensa esporulação.

$\mathrm{Na}$ maioria das plantas tratadas a $40^{\circ} \mathrm{C}$ houve também evolução normal dos sintomas da moléstia. Nos casos em que a duração total do tratamento a $40^{\circ} \mathrm{C}$ foi de 16 horas ou mais, não se formaram as pústulas, isto é, a moléstia não evoluiu.

No quadro 1 constam os resultados do tratamento térmico a $40^{\circ} \mathrm{C}$, dos cafeeiros inoculados com a raça II de $\mathbf{H}$. vastatrix.

Nas plantas "R", onde não houve esporulação, os pontos cloróticos permaneceram estáveis, indicando que não ocorreu evolução dos sintomas, mesmo 60 dias após a inoculação. Não se observou necrose nos tecidos, embora as áreas cloróticas com 2 a $3 \mathrm{~mm}$ de diâmetro se apresentassem levemente deprimidas. 
QUADRO 1. - Dados do ensaio para verificação do efeito de temperatura elevada, sobre a evolução da ferrugem - alaranjada em plantas de café mundo-novo, com seis meses de idade (*)

\begin{tabular}{|c|c|c|c|c|c|c|}
\hline \multirow{2}{*}{\multicolumn{2}{|c|}{ N. ${ }^{\circ}$ de exposiçōes }} & \multicolumn{5}{|c|}{ Tempo (horas) de exposição a $40^{\circ} \mathrm{C}$} \\
\hline & & 1 & 2 & 3 & 4 & $\mathbf{0}$ \\
\hline 1 & $\ldots \ldots \ldots \ldots \ldots \ldots \ldots$ & $\mathbf{E}$ & $\mathbf{E}$ & $\mathbf{E}$ & $\mathbf{E}$ & $\mathbf{E}$ \\
\hline 2 & $\ldots \ldots \ldots \ldots \ldots \ldots \ldots$ & $\mathbf{E}$ & $\mathbf{E}$ & $\mathbf{E}$ & $\mathbf{E}$ & - \\
\hline 3 & $\ldots \ldots \ldots \ldots \ldots \ldots \ldots$ & $\mathbf{E}$ & $\mathbf{E}$ & $\mathbf{E}$ & $\mathbf{E}$ & - \\
\hline 4 & $\ldots \ldots \ldots \ldots \ldots \ldots \ldots$ & $\mathbf{E}$ & $\mathbf{E}$ & $\mathbf{E}$ & $\mathbf{R}$ & 一 \\
\hline 5 & $\ldots \ldots \ldots \ldots \ldots \ldots \ldots$ & $\mathbf{E}$ & $\mathbf{E}$ & $\mathbf{E}$ & $\mathbf{R}$ & - \\
\hline 6 & $\ldots \ldots \ldots \ldots \ldots \ldots \ldots$ & $\mathbf{E}$ & $\mathbf{E}$ & $\mathbf{E}$ & $\mathbf{R}$ & - \\
\hline
\end{tabular}

(*) $\mathbf{E} \doteq$ plantas com evolução das pústulas de ferrugem;

$\mathbf{R}=$ sem pústulas, $\mathbf{i}$. é, evolução da ferrugem reprimida (H. vastatrix, raça II).

\section{4 - DISCUSSĀO E CONCLUSÕES}

Os resultados obtidos confirmam observações feitas sobre a evolução da ferrugem nas condiçōes tropicais e subtropicais do Brasil. As diversas regiões analisadas mostram diferentes padrões de curva epidemiológica. Regiōes com elevada temperatura, apesar do verão úmido, apresentam um mínimo de infestação nesse período.

Os dados demonstram que altas temperaturas impedem o desenvolvimento normal de Hemileia vastatrix, sendo letais mesmo quando o micélio já está estabelecido no interior da lâmina foliar. Todavia, é necessário que a exposição à temperatura elevada seja suficientemente longa.

Resultados seguros foram obtidos apenas a partir do tratamento térmico por quatro horas repetido quatro vezes: houve paralisação da evolução dos sintomas, seguida de morte do patógeno dentro de tecido vegetal.
As condições do estudo, embora artificiais, reproduzem em parte situações que normalmente ocorrem na maioria das regiôes onde o café é cultivado Nos meses de verão, temperaturas de $40^{\circ} \mathrm{C}$ ocorrem com frequiência na face das folhas expostas à luz solar direta. Nessas condições o ciclo epidemıológico da ferrugem é retardado, não obstante serem favoráveis ao desenvolvimento do fungo os demais fatores climáticos.

Os dados de campo, no geral são baseados em temperaturas do ar obtidas em abrigos próximos à planta. Dessa forma, é possível que ocorra uma diferença entre a temperatura anotada e aquela que realmente ocorre na superfície foliar. Moraes e colab. (9) concluiram que temperaturas do ar de $31^{\circ} \mathrm{C}$, medidas em abrigo micrometeorológico, foram suficientes para dilatar o período de incubação da ferrugem de cafeeiros a pleno sol, quando comparados com plantas mantidas à sombra, onde as temperaturas do ar não atingiam aquele valor. 
A diferença entre temperatura ambiente e da superfície foliar foi estudada por Campbell e Dimock (1), que verificaram que folhas de crisântemo expostas à luz solar direta apresentavam $9^{\circ} \mathrm{C}$ acima da temperatura ambiente. Como consequiência, Puccinia chrysanthemi, cuja temperatura letal é de cerca de $30^{\circ} \mathrm{C}$, podia ser erradicada mesmo quando a temperatura do ar era favorável a um contínuo desenvolvimento do patógeno.

Cafeeiros inoculados e mantidos a pleno sol sempre apresentam nú- mero de pústulas por folha menor do que quando mantidos em condições de sombreamento. Ortolani e colab. (12) mostraram que a incidência da ferrugem é sempre maior na face de exposição da planta que recebe menor radiação solar. Isso prolonga o molhamento das folhas, além de manter as temperaturas máximas em níveis inferiores aos das outras faces.

Os dados do presente trabalho fornecem subsídios para um melhor conhecimento do ciclo epidemiológico da moléstia.

\section{EFFECT OF TEMPERATURE ON COFFEE RUST EVOLUTION}

\section{SUMMARY}

The development of rust epidemics in tropical conditions of Brazil has been different than previously expected.

Despite of high humidity the development is reduced to a minimum during the summer. High temperature was assumed to have a detrimental effect on the rust development.

This paper reports the results of a study concerning the effect of high temperature on Hemileia vastatrix development.

Temperature treatment of inoculated young plants at $40^{\circ} \mathrm{C}$ for 4 hours in 4 consecutive days was sufficient to prevent rust development. The curative effect was permanent indicating that the fungus was destroyed inside the plant tissue.

Practical implications of such results are considered.

\section{LITERATURA CITADA}

1. CAMPBETL, C: E. \& DIMOCK, A. W. Temperature and the geographical distribution of chrysanthemum rust. Phytopathology 45:644-648, 1955.

2. EVEXRSMEYER, M. G. \& BURLEIGH, J. R. Effect of temperature on the longevity of Puccinia recondita $f$. sp. tritici urediospores on dry wheat foliage. Plant Dis. Reptr 52(3):186-188, 1968.

3. FUTREIL, M. C. \& RIVERS, G. W. The effect of temperature on the response of oats to race 216 of crown rust. Plant Dis. Reptr $39: 853-858,1955$.

4. HART, $H$. \& ZALESKI, $K$. The effect of light intensity and temperature on infection of hope wheat by Puccinia graminis tritici. Phytopathology 25:1041-1066, 1935.

5. HOBBS, E. L. Some factors affecting germinability of urediospores of Puccinia coronata. Phytopathology 52:1223-1225, 1962. 
6. HWANG, L. The effect of light and temperature on the viability of urediospores of certain cereal rusts. Phytopathology 32:699-711, 1942.

7. JOENSON, T. \& NEWTON, M. The effect of high temperature on uredial development in cereal rust. Can. J. Res. 15:425-432, 1937.

8. JOFNSON, T. \& NEWTON, M. The effect of high temperature on the stem rust resistance of wheat varieties. Can. J. Res. 19:438-445, 1941.

9. MORAES, S. A.; SUGIMORI, M. H.; RIBEIRO, I. J. A.; ORTOI.ANI, A. A. \& PEDRO Jr., M. J. Perído de incubação de Hemileia vastatrix Berk. et Br. em três regiōes do Estado de Sāo Paulo. Summa Phytopathologica 2(1):32-38, 1976.

10. NUTMAN, E. J. \& ROBERTS, F. M. Studies on the biology of Hemileia vastatrix Berk. et Br. Trans. Brit. mycol. Soc. 46(1) :27-48, 1963.

11. OLIVEIRA, BRANQUINHO d'. Estudos sobre Puccinia anomala Rost. III. Ação dos fatores ambientes sobre o comportamento das raças fisiológicas. Agron. lusit. 1(1) :64-87, 1939.

12. ORTOLANI, A. A. e colab. Níveis de infecção da ferrugem do cafeeiro nas exposiçōes norte e sul das plantas observadas em duas comunidades de Coffea arabica L. 2. Congresso Brasileiro Sobre Pesquisas Cafeeiras. Poços de Caldas, 1974, p. 132-134, (Resumos) 